\title{
Educação Anarquista: Uma proposta
}

\section{Anarchist Education: A proposal}

\author{
OLEGÁRIO, Hilson Santos. Mestre/Licenciado em Filosofia \\ Programa de Pós-Graduação PROF-FILO UFPE. Centro de Filosofia e Ciências Humanas - CFCH $15^{\circ}$ Andar, Cidade \\ Universitária - Recife-PE - CEP: 50740-550 / Telefone: (81) 2126-8297 / E-mail:/ hilson.professor@gmail.com
}

\section{Resumo}

Este artigo aborda parte de uma pesquisa realizada pelo Mestrado Profissional de Filosofia da Universidade Federal de Pernambuco - UFPE. A intervenção foi praticada numa sala de aula do primeiro ano do Ensino Médio durante a disciplina de filosofia, buscando favorecer o aprendizado de temas filosóficos pelo estudante através de um ensino considerado anarquista, o qual tem o intento de favorecer a autonomia e a responsabilidade do estudante na construção de seu próprio aprendizado em conexão com a sua realidade. Pensada como uma possibilidade para evitar uma educação homogênea e autoritária, tal experiência foi fundamentada no horizonte conceitual do pensador francês Gilles Deleuze (2010), dentro de sua perspectiva apontada com antihierárquica chamada por ele de rizomática em oposição ao modelo arborescente; junto a isto veremos algumas críticas de pensadores anarquistas em relação à educação capitalista e à sua reprodução da exploração. Utilizamos comentadores como Silvio Gallo, pois nos ajudam a fazer um deslocamento conceitual das obras deleuzianas numa adaptação para a realidade brasileira. Trabalharemos assim com desterritorializações, reterritorializações e atualizações como processos contínuos do pensamento, os quais resultam no próprio aprendizado com a sua crítica e a criação conceitual, tendo como nosso objeto de observação a sala de aula: desde uma compreensão de educação menor, distante das instâncias da educação maior como coordenações, secretarias e ministério, possuindo, essencialmente, a função de impedir a reprodução da homogeneidade e da heteronomia do que se deve e quando aprender encontrada na educação tradicional.

Palavras-chave: Filosofia, Educação, Deleuze.

\begin{abstract}
This article addresses part of a research carried out by the Professional Master of Philosophy at the Federal University of Pernambuco - UFPE. The intervention was practiced in a classroom of the first year of High School during the discipline of philosophy, seeking to favor the learning of philosophical themes by the student through a teaching considered anarchist, which aims to favor the autonomy and responsibility of the student in building your own learning in connection with your reality. Conceived as a possibility to avoid a homogeneous and authoritarian education, this experience was based on the conceptual horizon of the French thinker Gilles Deleuze, within his perspective pointed out with anti-hierarchical, which he called rhizomatic as opposed to the arborecent model; along with this we will see some criticisms from anarchist thinkers in relation to capitalist education and its reproduction of exploration. We use commentators like Silvio Gallo, as they help us to make a conceptual shift of Deleuzian works in an adaptation to the Brazilian reality. We will thus work with deterritorializations, reterritorializations and updates as continuous processes of thought, which result in the learning itself with its criticism and conceptual creation. The classroom is observed from an understanding of minor education, distant from instances of higher education such as coordination, secretariats and ministry, its function is to prevent the reproduction of homogeneity and heteronomy of what should and when to learn found in traditional education.
\end{abstract}

Keywords: Philosophy, Education, Deleuze. 


\section{1 - INTRODUÇÃO}

Neste texto escrito para o III Sertão Filosófico, trabalharemos parte de minha pesquisa no Mestrado Profissional de Filosofia, uma intervenção realizada com a turma do $1^{\circ}$ ano $\mathbf{B}$ da Escola Estadual Nossa Senhora da Apresentação, no estado de Alagoas, na cidade de Porto Calvo, no ano de 2018, nos meses de março e abril. Para a sua realização, adotamos como parâmetro o pensamento do francês Gilles Deleuze, a partir de sua obra 0 que é a filosofia? Neste trabalho encontraremos a exposição de como chegamos a este pensador, bem como demonstraremos um exemplo sobre como os seus conceitos e a sua filosofia poderão ser aplicados no contexto do ensino de filosofia, destinado ao público do Ensino Médio brasileiro.

Simplesmente chegou a hora, para nós, de perguntar o que é a filosofia. Nunca havíamos deixado de fazê-lo, e já tínhamos a resposta que não variou: a filosofia é a arte de formar, de inventar, de fabricar conceitos. Mas não seria necessário somente que a resposta acolhesse a questão, seria necessário também que determinasse uma hora, uma ocasião, circunstâncias, paisagens e personagens, condições e incógnitas da questão. Seria preciso formulá-la "entre amigos", como uma confidencia ou uma confiança, ou então face ao inimigo como um desafio, e ao mesmo tempo atingir esta hora, entre o cão e o lobo, em que se desconfia mesmo do amigo. É a hora em que se diz: "era isso, mas eu não sei se eu disse bem, nem se fui assaz convincente". E se percebe que importa pouco ter dito bem ou ter sido convincente, já que de qualquer maneira é nossa questão agora. (DELEUZE, 2010, p. 10).

Indicaremos como tal abordagem pode ser entendida dentro de uma perspectiva de pensamento sobre uma proposta de ensino libertário para esta disciplina em questão. No entanto, não pretendemos servir de manual que deva ser seguido à risca, mas buscamos ser entendidos como uma sinalização para uma fuga criativa que visa sair deste território de ensino delimitado previamente, com os seus quadrados perfeitos, onde tudo se explica a partir de uma unidade que se impõe, gerando as suas derivações dentro de um domínio nesta ordem imposta, chamada por Deleuze de pivotante ${ }^{1}$. Não temos o interesse em sua reprodução como um método, a menos que vise a sua transformação e a sua superação, afim de favorecer a emancipação do estudante diante das suas responsabilidades, em suas escolhas e na formação de seu aprendizado.

No trajeto inicial de nossa pesquisa, realizamos a leitura começando por seu amigo e também pensador contemporâneo, Michel Foucault. Observamos a sua valorosa contribuição na perspectiva da construção histórica das escolas, também o seu trato diferenciado de acordo com as suas meticulosas considerações com respeito às relações de poder presentes no processo disciplinar da educação escolar, com suas ferramentas de controle e de manutenção. Quanto às relações de poder, a disciplina e o exame, Foucault (1984) é direto:

A disciplina implica um registro contínuo. Anotação do indivíduo e transferência da informação debaixo para cima, de modo que, no cume da pirâmide disciplinar, nenhum detalhe, acontecimento ou elemento

1. Uma ordem pivotante é aquela derivada de uma unidade hierárquica de base, desenvolve-se de forma binária a qual suas ramificações ou derivações dependem necessariamente da unidade central, então suas variações giram em torno desta unidade como um pivô. 
disciplinar escape a esse saber. No sistema clássico o exercício do poder era confuso, global e descontínuo. Era o poder do soberano sobre grupos constituídos por famílias, cidades, paróquias, isto é, por unidades globais, e não um poder contínuo atuando sobre o indivíduo. A disciplina é o conjunto de técnicas pelas quais os sistemas de poder vão ter por alvo e resultado os indivíduos em sua singularidade. É o poder de individualização que tem o exame como instrumento fundamental. 0 exame é a vigilância permanente, classificatória, que permite distribuir os indivíduos, julgá-los, medi-los, localizá-los e, por conseguinte, utilizá-los ao máximo. Através do exame, a individualidade torna-se um elemento pertinente para 0 exercício do poder. (FOUCAULT, 1984, p. 106).

Posteriormente, ao lermos também algumas publicações do professor Silvio Gallo, desenvolvidas a partir de um direcionamento para a elaboração de uma proposta de educação anarquista; de maneira tal que esta é entendida como uma educação que valoriza tanto a liberdade, como também a autonomia e a responsabilidade do estudante em relação ao próprio ato de aprender; vista, também, como uma crítica feita ao que é ofertado para o aprendizado no modo de ensino homogeneizante, reprodutivo e hierarquizado encontrado na educação tradicional, apesar de ser considerada capitalista, encontramos na história da educação no Brasil a educação tradicional executada também na educação pública estatal em suas várias esferas Federais, Estaduais e Municipais, com sua gratuidade garantida, desde o início da República. Tal observação e procura, nos levou, então, ao desenvolvimento conceitual deleuziano e ao seu desdobramento para a elaboração de uma proposta de educação entendida como rizomática, aplicada nesta Escola Pública da pesquisa, por ocasião de ser local de trabalho na época e pela exigência do programa de mestrado profissional de filosofia -UFPE- de haver uma intervenção em sala de aula. No tocante ao ensino oferecido na escola pública, Gallo (2002) nos diz:

Assim, a escola pública que temos é a escola pública que o Estado nos quer financiar, seja ela legitimadora da dominação, seja ela o mecanismo distribuidor de um arremedo de educação que mantenha o povo em um estado de semi-ignorância e apatia político-social, pareça isso um descaso do Estado com a educação pública ou não. (GALLO, 2002a, p.153).

Deste modo, mesmo que possa parecer contraditória tal proposta, ela é realizada dentro das possibilidades concretas dos acontecimentos, numa escola pública de região canavieira, numa sociedade predominantemente cristã (católicos e evangélicos), despreocupada com as consequências políticas de seus gestores públicos. Por isto, este intento visa de alguma maneira superar tais condicionantes partindo do que está dado, não o tomando como estabelecido.

\section{1 -MAS QUE ANARQUIA É ESTA?}

A palavra Anarquia é constituída por duas raízes de origem grega. Uma derivada da arché, a palavra archon que significa governante; mais o prefixo an, que significa sem. Deste modo, como podemos observar a palavra em si nos indica simplesmente uma ausência de governo externo, ausência de um governante. Porém, no desenvolvimento do conflito da narrativa histórica, mesmo para uma dada concepção democrática e para aqueles que têm ideais de manutenção de uma 
sociedade fechada, hierarquizada, autoritária, o anarquismo advém pejorativamente de três fontes: da desordem ou baderna, da violência e do terrorismo. Frisamos que não é esta a nossa compreensão. No entanto, por perceber a existência de vários anarquismos dentro da proposta libertária, e para evitarmos tais enganos, preferimos entender a legitimidade de tal movimento como não-violento e que, através da educação, seja possível realizar as transformações pertinentes a cada sociedade em busca da liberdade individual desde que compreendida coletivamente.

Dentro da atividade do estudo do pensamento filosófico libertário, comumente podemos encontrar em muitos pensadores o entendimento da necessidade de eliminação da interferência do Estado, da Religião e da Propriedade diante das decisões individuais no tocante a uma sociedade formada com cidadãos instruídos integralmente. No entanto, mesmo com a impossibilidade de abordar toda a variedade do pensamento libertário, como também não temos a preocupação de determinar a sua pretensa origem, embora alguns autores façam tais estimativas, e dificilmente abordaremos com completude as suas divergências ideológicas em uma publicação que trate de educação, ensino de filosofia e anarquismo, mas reservamos alguns exemplos pertinentes ao ponto da valorização da educação como também da eliminação de obstáculos à liberdade, exporemos em certa medida o que encontramos em teóricos anarquistas que caminhamos ao encontro de alguns de seus posicionamentos, e também discordando em outros como, por exemplo, em relação a ações que levem à violência. Portanto, acreditamos que a educação seja a melhor ferramenta de libertação e de emancipação do indivíduo, e que, por isso, seja compreendido como no pensamento do primeiro teórico a se intitular anarquista, no sentido positivo do termo, Pierre-Joseph Proudhon (1975), que assim nos escreve sobre a concretização da educação completa:

Exponho uma verdade de que tentamos, inutilmente, impedir a eclosão; escrevo o preâmbulo da nossa futura constituição. Se as preocupações nos permitissem ouvir esta definição que vos parece blasfema, a propriedade é o roubo, teríamos o aguilhão mágico da tempestade; mas quantos interesses, quantos preconceitos se opõem a isso!... A filosofia não modificará em nada o curso dos acontecimentos: os destinos cumprir-se-ão independentemente da profecia: aliás, não é preciso que se faça justiça e a nossa educação se complete? (PROUDHON, 1975, p. 11).

Esta completude da educação, na visão anarquista, se dá na realização de uma educação integral, na qual as capacitações dos indivíduos compreendem trabalhos intelectuais e trabalhos manuais, sem hierarquia ou diferenciações sociais geradoras de explorações; ou quando encontramos nos escritos de Malatesta (2009) que em suas notas sem nenhuma datação, mas com perspectivas de seu surgimento como:

E quando alguns consideraram que a causa fundamental do mal era a luta
entre os homens que resultava no domínio dos vencedores e a opressão e a
exploração dos vencidos, e viram que este domínio dos primeiros e esta
sujeição dos segundos deram origem à propriedade capitalista e ao Estado,
e quando se propuseram derrubar o Estado e a propriedade, nasceu o
anarquismo. (MALATESTA, 2009, p. 05).

Pois, mesmo reconhecendo a natureza da busca filosófica pela origem, nós partimos do entendimento de que o anarquismo já está em desenvolvimento, e, a determinação de sua gênese, independente de datação e personagem conceitual não contribuirá de forma significativa ao 
pensamento libertário diante a sua vasta produção teórica, com as suas diversas expressões de posicionamento. 0 que nos leva a acreditar que o seu desdobramento e difusão, as suas críticas e suas reformulações são a comprovação do avanço do conceito de liberdade. Não estando preso a um livro sagrado ou a uma personalidade, o pensamento libertário se contradirá caso não se reavalie e irrompam novas propostas de superação da sociedade em busca da liberdade.

Em consonância com esta mesma visão quanto o que há de comum no pensamento libertário, também há o estudioso da história e das ideias anarquistas Woodcock (2002) que nos diz:

É a ideia geral proposta por Proudhon em 1840 que estabelece uma ligação entre ele e outros anarquistas surgidos mais tarde, como Bakunin e Kropotkin, e também com certos filósofos que viveram antes e depois dele, como Godwin, Stirner e Tolstoi, que criaram sistemas antigovernamentais sem aceitar a designação de anarquistas; e é nesse sentido que irei tratar o anarquismo, apesar de suas muitas variantes: como um sistema de filosofia social, visando promover mudanças básicas na estrutura da sociedade e, principalmente - pois esse é o elemento comum a todas as formas de anarquismo -, a substituição do estado autoritário por alguma forma de cooperação não-governamental entre indivíduos livres. (WOODCOCK, 2002, p. 11).

Assim, trabalhamos nesta perspectiva o ensino de filosofia trazendo a substituição do autoritarismo da educação tradicional por uma educação de cooperação mútua com o diálogo no processo do aprendizado, favorecendo mudanças básicas na autonomia e na responsabilidade do estudante quanto a sua construção do conhecimento, visando sua emancipação integral na sua formação para a cidadania. Dito isto, podemos indicar uma preocupação dos anarquistas com uma educação sem privilégios, a fim de evitar uma dominação através da posse do conhecimento, nas palavras de Bakunin (1979) podemos encontrar:

A primeira questão que vamos considerar hoje é esta: poderá a emancipação das massas ser completa, enquanto a instrução que as massas recebem for inferior aquelas que é dada aos burgueses, ou enquanto houver uma classe qualquer em geral, numerosa ou não, mas que, pelo seu nascimento, seja chamada aos privilégios de uma educação superior e duma instrução mais completa? Por esta questão, não é resolvê-la? Não será evidente que entre dois homens dotados de um inteligência natural aproximadamente igual, cujo espírito estiver mais aberto para a ciência, e que, tendo compreendido melhor o encadeamento do fatos naturais e sociais, ou aquilo que se chama leis da natureza e da sociedade, se aperceberá mais fácil e globalmente do caráter do meio em que vive, - que este se sentirá, digamos, mais livre, que será praticamente mais hábil e mais poderosos do que o outro? Aquele que sabe mais dominará naturalmente aquele que sabe menos; e se existir entre duas classes apenas essa diferença de educação e de instrução, esta diferença produzirá em pouco tempo todas as outras, o mundo humano voltará a seu estado atual, isto é, será dividido de novo numa massa de escravos e num pequeno número de dominadores, os primeiros trabalhando, como hoje, para os segundos. (BAKUNIN, M. 1979, p. 32).

O que Bakunin nos alerta, ainda no século XIX, é que a simples distinção do quê e do como é ensinado para os estudantes produz e reproduz determinadas relações de dominação, originandose neste caso, um domínio dos que sabem mais sobre os que sabem menos dentro da sociedade, trazendo por conseguinte o surgimento das demais estruturas de domínio. 
Deste modo, com o interesse de compreender a crítica do pensamento libertário à sociedade ocidental capitalista, temos Foucault que, embora não se declare anarquista, oferece uma contribuição valorosa a partir de suas ideias, compartilhadas através das publicações de seus livros, as quais vão nos desvelar a dinâmica de uma microfísica do poder (1987) como também na senda da criação das escolas chegamos ao seu livro Vigiar e punir: nascimento da prisão (1984). A partir de suas obras, Foucault nos fala das muitas etapas no desenvolvimento da construção histórica de processos disciplinares de formação, estas etapas estando presentes em nosso cotidiano nas várias instituições, nos trazendo uma submissão e realizando uma formação a partir da sujeição do indivíduo que tem início em nossa vida social desde a instituição familiar, seguida na educação infantil e transmitida panopticamente por outros espaços sociais:

A “invenção" dessa nova anatomia política não deve ser entendida como uma descoberta súbita. Mas como uma multiplicidade de processos muitas vezes mínimos, de origens diferentes, de localizações esparsas, que se recordam, se repetem, ou se imitam, apoiam-se uns sobre os outros, distinguem-se segundo seu campo de aplicação, entram em convergência e esboçam aos poucos a fachada de um método geral. Encontramo-los em funcionamento nos colégios, muito cedo; mais tarde nas escolas primárias; investiram lentamente o espaço hospitalar; e em algumas dezenas de anos reestruturam a organização militar. Circularam às vezes muito rápido de um ponto a outro (entre o exército e as escolas técnicas ou os colégios e liceus), às vezes lentamente e de maneira mais discreta (militarização insidiosa das grandes oficinas). A cada vez, ou quase, impuseram-se para responder a exigências de conjuntura: aqui uma inovação industrial, lá a recrudescência de certas doenças epidêmicas, acolá a invenção do fuzil ou as vitórias da Prússia. O que não impede que se inscrevam, no total, nas transformações gerais e essenciais que necessariamente serão determinadas. (FOUCAULT, 1987, p. 110).

Após ter uma familiaridade com o desenvolvimento do pensamento foucaultiano, observando a aproximação com Deleuze, em seu livro: A dobra: Leibniz e o barroco (1991), neste livro, o francês dá seu tratamento a natureza das questões de grandezas infinitas sobre a ótica do pensamento leibniziano, em um desenvolvimento argumentativo e seguindo a lógica de tal pensamento, Deleuze (1991) nos fala:

Dobrar-desdobrar já não significa simplesmente tender-destender,
contrair-dilatar, mas envolver-desenvolver, involuir-evoluir. O organismo
define-se pela capacidade de dobrar suas próprias partes ao infinito e
desdobrá-las não ao infinito, mas até o grau de desenvolvimento
consignado a espécie. Desse modo, um organismo está envolvido na
semente (pré-formação dos órgãos) e as sementes, como bonecas russas,
estão envolvidas umas nas outras até o infinito. (DELEUZE, 1991, p. 21).

Partindo deste mesmo pensamento, Deleuze nos afirma que o próprio plano de imanência, a abrangência do conceito deleuziano então teria duas faces, uma como pensamento e outra como natureza; entendida como Physis e também como Noüs, declarando que sempre haveria deste modo infinitos movimentos entrelaçados uns nos outros, dobrando-se uns nos outros, de maneira que o retorno de um nos traz o outro instantaneamente, fazendo com que o plano de imanência não pare de se tecer. Com o desenvolvimento da pesquisa que realizamos, voltada a uma visão de educação 
em prol de uma formação emancipatória do estudante, entendida, portanto, como anarquista, conhecemos o livro do professor Silvio Gallo, Educação anarquista: um paradigma para hoje (1996), a partir do qual podemos destacar uma preocupação e um debate sobre as relações de poder, dentre as quais, destaca-se o abuso da autoridade do professor, do autoritarismo em sala de aula pela figura do professor, além de outras relações de poder nos mais diversos setores educacionais e, ou de saberes, quando em tom de questionamento ele nos faz um desafio:

A equação saber é poder inscreve-se, pois, no contexto bem definido de uma sociedade estruturada sobre o modelo de exploração; a questão que nos propomos é a seguinte: essa equação é válida em todo e qualquer caso ou apenas no contexto da dominação? Ou, em outras palavras, seria possível superar a condição da vivência das relações de poder na escola? (GALLO, 1996, p. 55).

$E$, também, mais adiante, quando nos põe a observar a questão foucaultiana do espaço do poder e as suas engrenagens ao nos remontar as imagens de um professor tradicional e autoritário nas cenas do filme The wall, da banda de rock inglesa Pink Floyd:

Se tomamos a clássica concepção topológica do poder, devemos procurar o lugar específico que ele assume no mapa tático da educação, desdobrado sobre a sala de aula. Na concepção de educação que convenciou-se chamar de tradicional, o topos de poder é o corpo do professor; o poder encontrase nele encarnado, enquanto os alunos estão esvaziados dele. São a própria imagem da impotência no seu sentido estrito e literal. No filme The wall, dirigido por Alan Parker, com base em um álbum do grupo de rock inglês Pink Floyd, essa concepção ganha todas as cores e movimentos que a magia do cinema permite, apresentando o professor prepotente que age sobre seu alunos como um verdadeiro déspota, legitimado em sua posição pelo poder que possui, colocando para funcionar as engrenagens da máquina escolar que age ideologicamente sobre os alunos, no filme estrategicamente mostrada como um imenso moedor de carne que, primeiro retirando-lhes a individualidade - vão perdendo seus próprios rostos - uniformiza-os todos, transformando-os em carne moída. (GALLO, 1996, p. 55)

Junto a esta leitura, contamos também com a orientação do professor Dr. Sérgio Ricardo Vieira Ramos e vimos a possibilidade de a partir do pensamento deleuziano aprimorarmos tal empreendimento, pensado como contribuição para o ensino de filosofia para além das questões sobre conteúdo, método pedagógico, escola e currículo; mas sim, visto como uma ferramenta de favorecimento ao aprendizado do estudante, ao estabelecer contato com a filosofia através de um ensino visto como rizomático, com a intenção de realizar uma desterritorialização de um antigo conhecimento e de concretizar uma nova reterritorialização mais atualizada, chegando assim ao próprio desenvolvimento contínuo do aprendizado.

Embora o aprendizado seja um assunto presente na problemática do ensino em geral, reservamo-nos ao seguinte contexto: estudantes, residentes nas proximidades do município de Porto Calvo - AL, região do litoral norte alagoano, com uma economia predominantemente canavieira, tendo uma marcante influência do Brasil holandês e do Quilombo dos Palmares, através de Clabar e Zumbi, como personagens importantes e identitários, além da representação histórica, visto que também são tipos psicossociais naturais da cidade. Para esta experiência, utilizamos o 
desenvolvimento de conceitos deleuzianos num exercício de deslocamento conceitual aplicado para esta determinada intervenção. Aproveitamos a contribuição proposta pelo professor Silvio Gallo que faz uma abordagem deleuziana das questões próprias da educação, levando em consideração o Brasil particularmente. Gallo (2002) desenvolve seu deslocamento conceitual do pensamento deleuziano de uma literatura maior e uma literatura menor, para o que este professor chegou a chamar de uma educação maior e uma educação menor. Disto, segue-se:

A primeira característica é a da desterritorialização; se na literatura é a
língua que se desterritorializa, na educação a desterritorialização é dos
processos educativos. As políticas, os parâmetros, as diretrizes da
educação maior estão sempre a nos dizer o que ensinar, como ensinar, para
quem ensinar, porque ensinar. A educação maior procura construir-se como
uma imensa máquina de controle, uma máquina de subjetivação, de
produção de indivíduos em série. (GALLO, 2002b, p. 173).

Ao se reterritorializar na sala de aula, a educação menor se desterritorializa das instâncias tão distantes daquela realidade local e trata diretamente com os processos educativos não pensados pela educação maior, as particularidades e as diferenças no aprendizado de cada estudante inseridas daquele coletivo, visto que:

\begin{abstract}
A segunda característica é a ramificação política. Se toda educação é um ato político, no caso de uma educação menor isso é ainda mais evidente, por tratar-se de um empreendimento de revolta e de resistência [...] Por fim, a terceira característica é o valor coletivo. Na educação menor todo ato adquire um valor coletivo [...] $\mathrm{Na}$ educação menor, não há a possibilidade de atos solitários, isolados; toda ação implicará em muitos indivíduos. Toda singularização será, ao mesmo tempo, singularização coletiva. (GALLO, 2002b, p. 173-176).
\end{abstract}

A visão rizomática da sala de aula e suas ramificações vem de um deslocamento realizado por Deleuze desterritorializando este conceito da Biologia e o reterritorializando na Filosofia. Foi pretendido alcançá-la nos baseando através de princípios da caracterização de um rizoma conceitual deleuziano encontrado no seu livro: Mil platôs: capitalismo e esquizofrenia (2000). Tais princípios teoricamente são trabalhados mais adiante, mas salientamos o nosso ímpeto de criar uma proposta em oposição a todo modelo autoritário, hierárquico, verticalizado e homogeneizante. Fazemos esta crítica com um paralelo ao modelo encontrado na educação tradicional, reconhecendo-a no mesmo pensamento deleuziano, definido como modelo arborescente, rígido, fundamentado na imposição do uno e na sua divisão. Por assim dizer, em uma variedade baseada no máximo a partir de uma dicotomia que por sí só já deriva de uma imposição de uma unidade fundante (arché).

A árvore já é a imagem do mundo, ou a raiz é a imagem da árvore-mundo. É o livro clássico, como bela inferioridade orgânica, significante e subjetiva (os estratos do livro). O livro imita o mundo, como a arte, a natureza: por procedimentos que lhes são próprios e que realizam o que a natureza não pode ou não pode mais fazer. A lei do livro é a da reflexão, o Uno que se torna dois. Como é que a lei do livro estaria na natureza, posto que ela preside a própria divisão entre mundo e livro, natureza e arte? Um 
torna-se dois: cada vez que encontramos esta fórmula, mesmo que enunciada estrategicamente por Mao Tsé-Tung, mesmo compreendida o mais "dialeticamente" possível, encontramo-nos diante do pensamento mais clássico e o mais refletido, o mais velho, o mais cansado. A natureza não age assim: as próprias raízes são pivotantes com ramificação mais numerosa, lateral e circular, não dicotômica. (DELEUZE, 2000, p. 12).

Ao propor em seu pensamento que a natureza não age de forma dicotômica a partir do uno, Deleuze (2000) vai de encontro com a tradição e a sua imposição da arché, que visa um pensamento hegemônico para, então, nos propor um entendimento de várias multiplicidades para além desta dicotomia de construção autoritária. Ele nos traz um pensamento onde o entendimento é de que a natureza neste sentido é múltipla, com movimentos infinitos de rupturas e de continuidade.

\title{
2 - DESTERRITORIALIZAÇÃO: um começo de novo
}

\begin{abstract}
Acreditamos que os tipos psicossociais têm precisamente este sentido: nas circunstâncias mais insignificantes ou mais importantes, tornar perceptíveis as formações de territórios, os vetores de desterritorialização, o processo de reterritorialização. Mas não há, também, territórios e desterritorializações que não são somente físicas e mentais, mas espirituais - não somente relativas, mas absolutas, num sentido a determinar mais tarde? Qual é a Pátria ou o Chão Natal invocados pelo pensador, filósofo ou artista? A filosofia é inseparável de um Chão Natal, do qual dão testemunho também o a priori, o inato ou a reminiscência. Mas por que esta pátria desconhecida, perdida, esquecida, fazendo do pensador um Exilado? O que é que vai the devolver um equivalente de território, como valendo um lar? Quais serão os ritornelos filosóficos? Qual é a relação do pensamento com a Terra? (DELEUZE, 2010, p. 91).
\end{abstract}

Fazendo uma breve passagem pela história da educação brasileira e do ensino de filosofia no Brasil, conseguimos observar as muitas variações da política educacional que acompanham as mudanças do sistema de governo, da forma de governo e da política econômica em muitos momentos diferentes desta terra; modificando consequentemente, por sua vez, seu entendimento de territorialidade, a sua compreensão de sentido existencial e mantendo no ensino aquilo que convém de acordo com o interesse de determinados governos. Variações estas ditadas por grupos que se alternam no poder desde os tempos do Brasil-Colônia e que afetam diretamente a formação dos vários cidadãos em todo processo educacional, desde a criança como pessoa em formação até o que se esperar de um cidadão adulto. Visto isto, buscamos que os estudantes da cidade de Porto Calvo realizassem uma desterritorialização para poderem entrar em contato com a filosofia pela primeira vez num ambiente escolar e, posteriormente, se reterritorializarem numa construção de conhecimento, avançando para além da reprodução do "certo", de respostas repetidas, decalcando o aprendizado.

Realizada uma análise textual do pensador Gilles Deleuze (2002) em seu livro: O que é a filosofia?, num diálogo junto à sua proposta sugerida de uma experiência entendida como rizomática encontrada na parceria entre Deleuze e Guattari (2000) no seu livro Mil platôs - 
capitalismo e esquizofrenia, vol. I, deslocada para a educação numa proposta desenvolvida pelos seus comentadores, uma vez que Deleuze não aborde da forma aprofundada especificamente a questão da educação em geral e da educação filosófica, mas nos serve como referência, pois trabalha com muita originalidade o esforço do deslocamento conceitual no desenvolver de seu pensamento, o qual consideramos importante na concepção desta proposta de uma educação libertária, entendida numa visão rizomática para o ensino de filosofia, investigando as fontes para buscar, então, a determinação dos critérios e das ferramentas conceituais que evidenciem como acontecem as relações de ensino de filosofia com o processo de desterritorialização e reterritorialização para o desenvolver do nosso problema. Assim sendo, a partir desta perspectiva, Deleuze (2010) nos diz:

Conhecer-se a si mesmo - aprender a pensar - fazer como se nada fosse evidente - espantar-se, "estranhar que o ente seja"..., estas determinações da filosofia e muitas outras formam atitudes interessantes, se bem que fatigantes a longo prazo, mas não constituem uma ocupação bem definida, uma atividade precisa, mesmo de um ponto de vista pedagógico [...] 0 construtivismo exige que toda criação seja uma construção sobre um plano que lhe dá uma existência autônoma. Criar conceitos, ao menos, é fazer algo. A questão do uso ou da utilidade da filosofia, ou mesmo de sua nocividade (a quem ela prejudica?), é assim modificada. (DELEUZE, 2010, p. 15-16).

Percebe-se também que a simples inclusão da disciplina filosofia no currículo por si só não é garantia de que ela irá colaborar na formação humana, num conhecimento de si mesmo de um aspecto emancipatório, existencial e ético aos estudantes, no sentido de contribuir para uma compreensão e uma crítica dos saberes filosóficos, dos acontecimentos históricos, econômicos, políticos, culturais e ambientais que envolvem as várias transformações da sociedade que estão presentes, desde o nascimento até as relações da vida adulta.

Não se tratando assim, que a nossa proposta também não seja vista somente de repetições ilustradas e legitimadoras de postulados imortalizados no âmbito da filosofia e do ensino de filosofia, que visam a reproduzir o que está posto num horizonte apenas de capacitação de mão de obra para o trabalho e sua reprodução dos determinados tipos psicossociais almejados. Pretendemos ter uma base teórica fundamentada, mas sabemos que a prática requer uma lida que muitas vezes vai além da teoria e nos exige ações individuais criativas. Nas palavras do professor Silvio Gallo (2002), encontramos que tal procedimento educacional autoritário deve ser transgredido, eis o nosso objetivo, uma educação anarquista como forma de impedir esta reprodução heteronômica:

As táticas de uma educação menor em relação à educação maior são muito parecidas com as táticas de grevistas numa fábrica. Também aqui se trata de impedir a produção; trata-se de impedir que a educação maior, bempensada e bem-planejada, se instaure, se tome concreta. Trata-se de opor resistência, trata-se de produzir diferenças. Desterritorializar. Sempre. (GALLO, 2002b, p. 174).

Reconheça-se por outro lado aqui a importância dos profissionais de educação, ativistas de vários setores da sociedade civil que lutam nas instituições por uma política educacional bem fundamentada e cidadã, com seus movimentos de avanços e retrocessos nas conquistas de garantias 
legais, de uma educação de formação para a cidadania na sociedade democrática capitalista em que vivemos. No entanto, reconhecemos a necessidade de contrariar esta ordem opressora com respaldo nas palavras do professor Silvio Gallo ao nos afirmar que:

$\mathrm{Na}$ educação trabalhada pelo sistema capitalista, cujo objetivo é perpetuar a sociedade de exploração: ela ensina os burgueses a explorar, dominando todos os conhecimentos disponíveis e não vendo outro modo de vida; e ensina as massas proletárias a permanecerem dóceis à exploração, não se rebelando contra o sistema social injusto [...] A educação capitalista não forma um homem completo, mas um ser parcial, comprometido com princípios definidos a priori e exteriores a ele; em outras palavras, a educação capitalista funda-se na heteronomia. (GALLO, 2010, p. 04).

Percebemos que dentro da perspectiva de uma educação maior, presente assim nas discussões das políticas educacionais, de dimensões tão amplas, com abrangências das formas legais; das esferas Federais, Estaduais, Municipais e Privadas; das Gestões Escolares, das Coordenadorias de ensino que seguem a ordem de uma hierarquia universalizante, onde na ponta da cadeia encontra-se cada estudante, visto de forma generalizada, homogeneamente com as mesmas condições e aptidões nas relações de ensino, entendendo-os quando muito dentro de uma diversidade a partir de uma mesma unidade subjetiva imposta como padrão.

Como consequência deste posicionamento, é necessário frisar que não se apreende daí o nosso território. Nosso amparo teórico podemos encontrar no posicionamento do teórico anarquista Mikhail Bakunin, dentre uma das muitas vezes em que faz a sua crítica aos modelos educacionais consolidados para não nos tornarmos cúmplices desta engrenagem de instrução homogênea, desta maneira ele nos diz que:

Todas as ideias, que ele encontra encarnadas nas coisas e nos homens, desde o seu nascimento, e que se imprimem no seu espírito pela educação e pela instrução que o indivíduo recebe, antes mesmo de se conhecer a si próprio, vai encontrá-las mais tarde consagradas, explicadas e comentadas por teorias que a consciência universal ou juízo coletivo e por todas as instituições religiosas, políticas e econômicas da sociedade que faz parte. $E$, ele próprio, está de tal modo impregnado com elas, quer esteja ou não pessoalmente interessado em defender, que reage involuntariamente, devido a todos os hábitos materiais, intelectuais e morais que o tornam cúmplice. (BAKUNIN, 1975, p. 12).

Diferentemente destas iniciativas generalizantes, buscou-se intervir em uma sala de aula específica apenas, desterritorializada das instâncias da macropolítica desta educação maior, mas entendendo-a como um rizoma, com as suas conexões e as suas rupturas e as demais partes de um todo de multiplicidades, presentes na sociedade a qual está inserida. De fato, nosso esforço de fazer surgir a multiplicidade acontece ao subtrair tal sala de aula das demais, pois entendemos que:

É preciso fazer o múltiplo, não acrescentando sempre uma dimensão superior, mas, ao contrário, da maneira simples, com força de sobriedade, no nível das dimensões de que se dispõe, sempre n-1 (é somente assim que o uno faz parte do múltiplo, estando sempre subtraído dele). Subtrair o único da multiplicidade a ser constituída; escrever a $n-1$. Um tal sistema poderia ser chamado de rizoma. (DELEUZE, 2000, p. 13 - 14). 
Ao subtrairmos esta turma para a pesquisa das demais turmas do primeiro ano da Escola, nos empenhamos em favorecer a possibilidade da constituição da autenticidade da multiplicidade deste primeiro ano diante das outras turmas. Com um cronograma de ensino de filosofia dentre estes dois meses (mar. e abr.) estruturado no diálogo com os estudantes, procuramos observar a realização das atividades favorecendo a criação de soluções que vinculam a filosofia e sua realidade. Ficou estabelecido que não haveria prova ou exame, mas sim a elaboração de um zine relacionado com as temáticas trabalhadas no período da intervenção e a sua divulgação com o intento de encontrar nesta sala de aula uma ligação com toda a cidade, com a região de entorno; a sua conexão com os papéis sociais da variada classe social que participa desta escola, desde filhos de fazendeiros, de pedreiros, de feirantes, até de donas de casa, etc. E, ao rompermos com a visão tradicionalista, favorecemos essa linha de fuga que nos faz diferentes das multiplicidades de turmas presentes nesta escola e das demais, vistas universalizadas numa perspectiva tradicional de ensino.

\section{3 - CONSIDERAÇÕES FINAIS}

A partir desta consistência existencial da intervenção foi elaborada a conexão dos temas filosóficos com a realidade dos estudantes presentes, os problemas foram surgindo espontaneamente apesar de um planejamento prévio próprio da pesquisa; temas como mitologia grega permeavam o fascínio dos estudantes, a partir de perguntas como: "Professor, o senhor é ateu?" deu-se início a um debate sobre religião etc. Isto colaborou como parâmetro para a observação na construção do que chamamos de mapas de aprendizado dos estudantes desta sala de aula, junto a isto realizamos a confecção de um material com os temas abordados em sala, como conhecimento, religião, cultura, ética e política. A produção do zine tanto serviu para demarcar a desterritorialização do conhecimento prévio dos estudantes vindo do fundamental II, como do mesmo modo reterritorializar materialmente tais aprendizados como ferramenta de transformação e crítica do momento de sua realização, também facilitou a questão da interação do indivíduo e da coletividade, atribuições e resoluções de tarefas. Apesar da precariedade infra-estrutural da Escola e das dificuldades de leitura dos estudantes, a turma dividiu-se em grupos e cada grupo abordou um tema específico. Após pesquisas e distribuições de atividades, estes grupos se propuseram a um debate onde teciam argumentos e verificavam sua validade ampliando seu conhecimento num movimento de desterritorialização, reterritorialização e atualização de si mesmo, finalizando com um movimento panfletário do zine produzido e de diálogos que foram além das salas de aula, ramificando conexões com outros estudantes e integrantes da comunidade escolar.

\section{REFERÊNCIAS}

Primária:

DELEUZE, G. GUATTARI, F. O que é a filosofia?. Tradutor: Bento Prado Jr.Alberto Alonso Munoz. 3a ed. São Paulo: Editora 34, 2010. 


\section{Secundária}

BAKUNIN, M. Socialismo libertário. Tradutor: Olinto Beckerman. São Paulo: Global Editora e Distribuidora, 1979.

O conceito de liberdade. Tradutor: Jorge Dessa. Porto: Edições Res Limitada, 1975.

DELEUZE, G. Diferença e repetição. Tradutor: Luiz Orlandi, Roberto Machado. Rio de Janeiro: Graal, 1988.

G. A dobra: Leibniz e o barroco. Trad. Luiz B. L. Orlandi.

Campinas, São Paulo: Papirus, 1991.

G.; GUATTARI, F. Mil platôs: capitalismo e esquizofrenia. 2a ed. São Paulo: Editora 34, 2000.

FOUAULT, Michel. Microfísica do poder. Org. Tradução: Roberto Machado. $4^{\mathrm{a}}$ ed. Rio de Janeiro: Graal, 1984.

Michel. Vigiar e punir: nascimento da prisão. Tradução Raquel Ramalhete. Petrópolis: Vozes, 1987.

GALLO, Silvio. Educação anarquista: um paradigma para hoje. Piracicaba: Ed. Unimep, 1995. , Silvio. A escola pública numa perspectiva anarquista. VERVE. № 01/2002a. ISSN: 16769090

Silvio. Em torno de uma educação menor. n. 27(2), p. 169-178, jul./dez. 2002 b.

MALATESTA, Errico. Anarquismo e anarquia. Tradução: Felipe Corrêa. Faísca: 2009.

PROUDOHN, J. O que é a propriedade?. 2a ed. Lisboa: Editorial Estampa, 1975.

SILVA, Tomaz Tadeu da. Documento de identidade: uma introdução às teorias do currículo. 2a ed. Belo Horizonte: Autêntica, 2005.

WOODCOCK, George. História das ideias e movimentos anarquistas - v. 1: a ideia. Tradutor: Júlia Tettamanzy. Porto Alegre: L\&PM Editores, 2002. 